\title{
Partially Oxidized Polydiphenylamine for Sensitive Electrochemical Determination of Ceftazidime
}

\author{
K. Zarei* and M. Lesani \\ School of Chemistry, Damghan University, Damghan, Iran
}

Received October 25, 2017; accepted April 12, 2018

\begin{abstract}
This work reports the development of a glassy carbon electrode (GCE), modified with an oxidized poly diphenylamine/multi-walled carbon nanotubes- $\beta$-cyclodextrin (OPDPA /MWCNT- $\beta$-CD) composite film, for ceftazidime determination. The OPDPA/MWCNT- $\beta$-CD film surface morphology was investigated using field emission scanning electron microscopy (FESEM) and cyclic voltammetry (CV). Ceftazidime was adsorbed onto the OPDPA/MWCNT- $\beta-C D$, at open circuit, for 240 seconds, and then oxidized in acidic media. The electrochemistry of ceftazidime oxidation was investigated using cyclic voltammetry and differential pulse voltammetry (DPV). Under optimum conditions, the peak current linearly increased with ceftazidime concentration, in the range of $5 \times 10^{-8} \mathrm{M}$ to $1 \times 10^{-5} \mathrm{M}$. The obtained detection limit was $1.0 \times 10^{-9} \mathrm{M}$. This sensor was employed for ceftazidime determination in the biological and pharmaceutical samples.
\end{abstract}

Keywords: oxidized poly diphenylamine, multi-walled carbon nanotube, $\beta$-cyclodextrin, ceftazidime, adsorptive differential pulse voltammetry, electropolymerization.

\section{Introduction}

Ceftazidime (Fig. 1) is one of the third-generation cephalosporin antibiotics that can affect both gram-positive and gram-negative bacteria. It is used to treat different diseases, such as pneumonia and lung infections, cystic fibrosis, urinary region diseases, skin and soft tissue infections, bone and contiguous putridity, peritonitis and other gastric infections. In spite of ceftazidime wide applications, it has some side effects, such as convulsions, hyperactivity, bloody diarrhea, and swelling and soreness at the injection site.

Therefore, the detection of this drug in the biological and pharmaceutical samples is very significant. Some analytical methods have been introduced for ceftazidime determination, such as spectrophotometric [1-4], chromatographic [5-6], capillary electrophoresis [7] and electrochemical [8-12] methods. Among

\footnotetext{
* Corresponding author. E-mail address: zarei@du.ac.ir
} 
different methods electrochemical ones are very interesting, due to their high sensitivity, selectivity and speed.<smiles>CC(C)(ON=C(C(=O)NC1C(=O)N2C(C(=O)[O-])=C(C[n+]3ccccc3)CSC12)c1csc(N)n1)C(=O)O</smiles>

Figure 1. Chemical structure of ceftazidime.

The electrical conductivity or charge transport features of conductive polymers enhance the linear dynamic range of the determination and responsiveness of the electrochemical sensors. The great benefit of conducting polymers based sensors is that they have the capability of presenting improved response qualities, and are sensitive to small disturbances [13]. The other advantage of some sensors based on conducting polymers is the avoidance of the electroactive compounds interference on the sensor electrochemical response [14]. Poly (diphenylamine) (PDPA), an N-substituted polyaniline derivative, is a conducting polymer which structure is similar to polyaniline (PANI). PDPA was used to alter the electrodes surface for the determination of different materials [15-19]. On the other hand, conductive polymers can be oxidized in more positive potentials, and turn into oxidized polymers. For example, polypyrrole, an important conductive polymer, has been overoxidized [20] and, consequently, the addition of oxygen-containing groups, such as carbonyl and carboxyl, to the polymer, led to great specificities such as cations exchange and molecular sieve features. In addition to the above mentioned properties, the background current was reduced. However, to the best of our knowledge, there is no report on PDPA oxidation for the making of electrochemical sensors, and there is also no report on ceftazidime determination by PDPA.

Carbon nanotubes (CNTs), one group of nanomaterials, have distinct chemical, electronic and mechanical properties. They can lead to simpler electrons transfer between the electroactive species and the electrode surface, and also contribute for the generation of modified electrodes in electrochemical sensors. Some reports display catalytic activity for sensors based on CNTs [21-24].

Cyclodextrins (CDs), as hosts, can produce the inclusion complex with different molecules, as guests, due to their structure that has hydrophilic covering and hydrophobic cavities (25).

There are some researches that have employed both CNTs and CD to modify the electrode surface [26-28].

In this work, a sensor designed for ceftazidime determination, based on oxidized poly (diphenylamine)/multi-walled carbon nanotube- $\beta$-cyclodextrin (OPDPA/MWCNT- $\beta-C D$ ), was explained. Adsorptive differential pulse 
voltammetry (AdDPV) was employed for ceftazidime electrochemical determination.

\section{Experimental \\ Apparatus and reagents}

An electrochemical analyzer, model 394 (PAR, Princeton Applied Research), and an Autolab electrochemical system with PGSTAT 12 (Eco-Chemie, Utrecht, The Netherlands) and with FRA 4.9 software, were utilized for voltammetric and electrochemical impedance experiments, respectively. The electrochemical system includes a three-electrode system with an OPDPA/MWCNT- $\beta$-CD/GCE as working electrode, $\mathrm{Ag} / \mathrm{AgCl} / \mathrm{KCl}$ (saturated) as reference electrode, and a platinum wire as auxiliary electrode. The surface area of the applied GCE was $0.0314 \mathrm{~cm}^{2}$. Field emission scanning electron microscopy (FESEM) was conducted with MIRA3TESCAN-XMU model.

Ceftazidime was generously prepared by Jaber Ebne Hayyan Pharmaceutical Co. (Iran). Diphenylamine was obtained from Merck. $\beta$-cyclodextrin and MWCNTs were bought from Sigma-Aldrich and Io-li-tec company, respectively.

\section{Fabrication of OPDPA/MWCNTs- $\beta$-CD composite modified electrode}

Firstly, MWCNTs were refined and functionalized as in our previous work [29]. Briefly, MWCNTs were heated at $350{ }^{\circ} \mathrm{C}$ for $2 \mathrm{~h}$ and, after cooling, they were ultrasonicated for $4 \mathrm{~h}$ in concentrated $\mathrm{HCl}$. After that, they were refined and rinsed with distilled water, and functionalized in a mixture of sulfuric acid and nitric acid in a $3: 1$ ratio, for $10 \mathrm{~h}$.

To provide MWCNT- $\beta$-CD/GCE, $10 \mathrm{mg}$ of MWCNT were combined with 10 $\mathrm{mL}$ of the $1.0 \mathrm{mM} \beta-\mathrm{CD}$ aqueous solution, and located in ultrasonic for $30 \mathrm{~min}$, to obtain dispersed MWCNT. Then, $4 \mu \mathrm{L}$ of the MWCNT- $\beta-\mathrm{CD}$ dispersion were cast onto the surface of well-polished GCE, and evaporated under an UV lamp. DPA electropolymerization was conducted on MWCNT- $\beta-\mathrm{CD} / \mathrm{GCE}$, by continuous cyclic voltammetry, in a $1.0 \mathrm{mM}$ monomer, and in $5 \mathrm{M} \mathrm{H}_{2} \mathrm{SO}_{4}$. To partially oxidize the polymer film, the potential of $0.9 \mathrm{~V}$ was applied to the working electrode for $180 \mathrm{~s}$.

\section{Procedure}

Proper amounts of ceftazidime in $0.15 \mathrm{M} \mathrm{HClO}_{4}$ were placed into the voltammetric cell. The accumulation was achieved on open circuit potential for $240 \mathrm{~s}$, whilst the solution was stirred. After the adsorption step, the stirrer was stopped and, after $5 \mathrm{~s}$ relaxation, the potential was altered from 0.4 to $0.6 \mathrm{~V}$ versus the $\mathrm{Ag} / \mathrm{AgCl}$ reference electrode, with a scan rate of $33.3 \mathrm{mVs}^{-1}$, using the differential pulse voltammetric method. A blank solution without ceftazidime was used to take the blank peak current. 


\section{Results and discussion}

\section{Oxidation of the polymer film}

During the polymer growth, two anodic peak currents appeared and increased (15): the first, at $0.55 \mathrm{~V}$, is assigned to the formation of $\mathrm{DPA}^{+}$cation radicals, and then dimers; and the second, at $0.75 \mathrm{~V}$, is probably related to the dimer or polymer oxidation [30]. Fig. 2 shows the peak current of PDPA/MWCNT- $\beta$ $\mathrm{CD} / \mathrm{GCE}$ in a $0.15 \mathrm{M} \mathrm{HClO}_{4}$ solution, before oxidation, for solutions with and without ceftazidime; a high current was seen for the blank solution, and one small peak was observed for ceftazidime, at $0.54 \mathrm{~V}$. However, after the polymer oxidation, at $0.9 \mathrm{~V}$, the blank current diminished (Fig. 2), the ceftazidime current increased, and a negative shift was observed in the anodic peak potential. The polymer oxidation was also investigated in the other solutions, such as $\mathrm{NaOH}$ and phosphate buffer solutions, with different $\mathrm{pH}$ values (in the range of 3.0 to 9.0), and the best response was obtained in $0.15 \mathrm{M} \mathrm{HClO}_{4}$. Potential and time were optimized to reach a weaker blank current, and also a stronger current for ceftazidime. On more positive potentials (higher than $0.9 \mathrm{~V}$ ), a sharper decrease in the blank current was observed, but the ceftazidime current also decreased, which may be related to the lower conductivity at higher potentials.

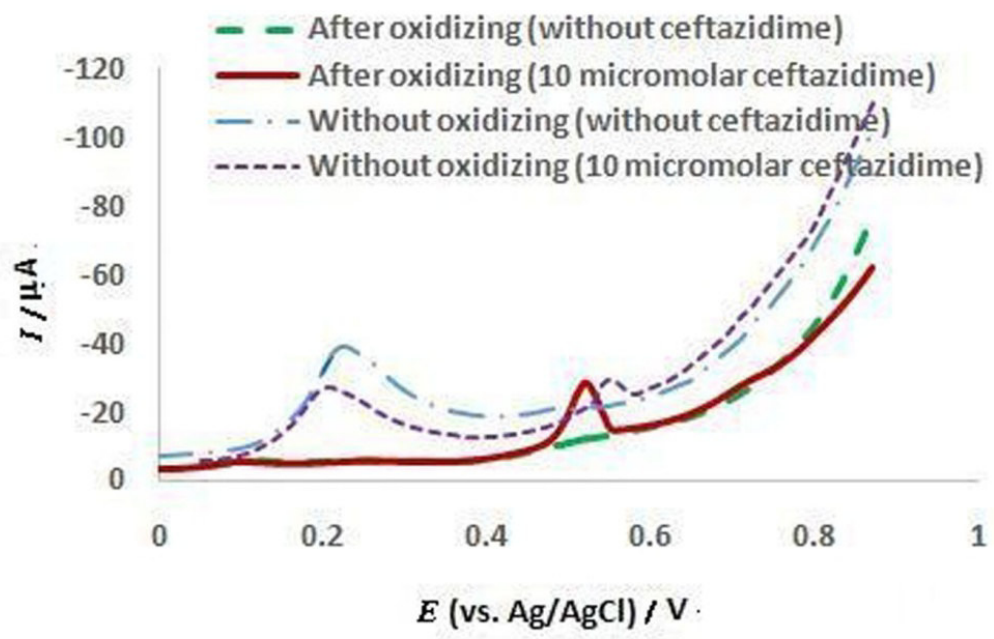

Figure 2. Differential pulse voltammograms recorded at PDPA/MWCNT- $\beta-C D / G C E$ and OPDPA/MWCNT- $\beta-\mathrm{CD} / \mathrm{GCE}$, in $0.15 \mathrm{M} \mathrm{HClO}_{4}$, for blank and ceftazidime solutions.

However, the results of impedance spectroscopy, in Fig. 3, confirm that oxidation at higher potentials can decrease the polymer conductivity.

Ofer et al. have also discovered that some polymers, such as polythiophenes, polyaniline, and polypyrroles, have finite potential dependent windows of high conductivity, as their conductivity increases with the increase in the oxidation potential, and then it decreases [31]. Therefore, in this work, oxidation was performed at $0.9 \mathrm{~V}$, for $180 \mathrm{~s}$. Cyclic voltammetry and field emission scanning electron microscopy (FESEM) were applied to characterize the polymer film, before and after oxidation. 


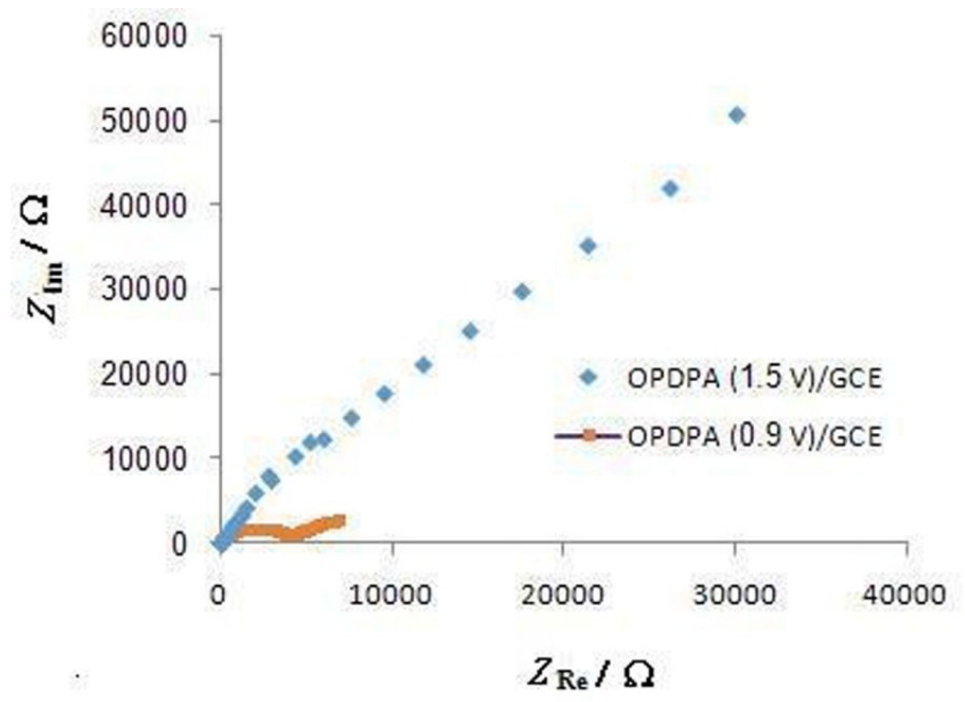

Figure 3. EIS of OPDPA (oxidized at 1.5 V)/GCE and OPDPA (oxidized at 0.9 $\mathrm{V}) / \mathrm{GCE}$, in $5 \mathrm{mM} \mathrm{Fe}(\mathrm{CN})_{6}{ }^{3-} / \mathrm{Fe}(\mathrm{CN})_{6}{ }^{4-}$ in $0.1 \mathrm{M} \mathrm{PBS}$, at $\mathrm{pH}$ 7. Applied AC voltage: 5 $\mathrm{mV}$, frequency: $0.1 \mathrm{~Hz}$ to $100 \mathrm{kHz}$.

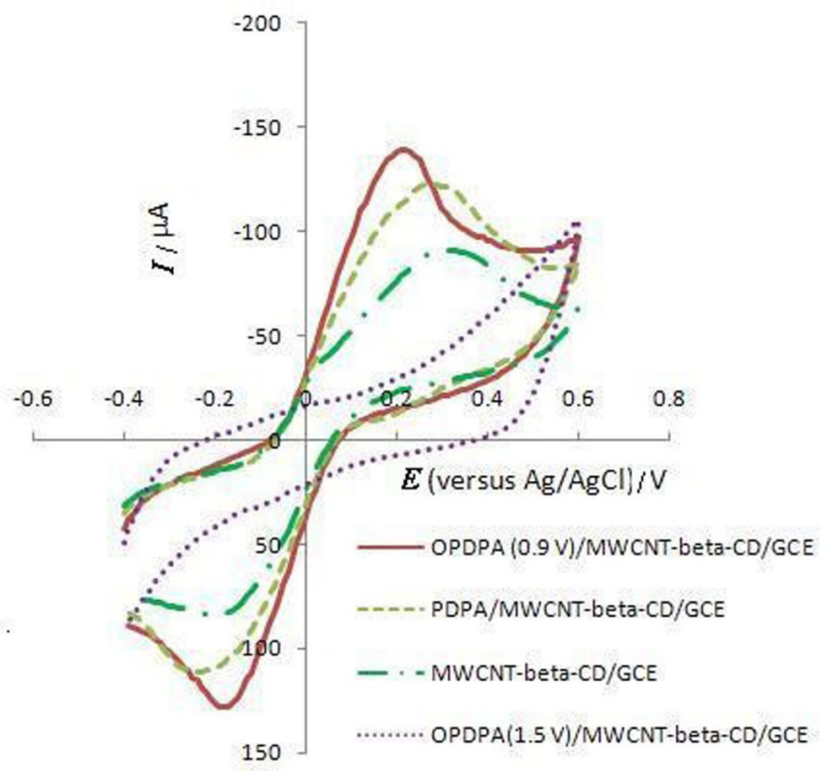

Figure 4. Cyclic voltammograms of MWCNT- $\beta-C D / G C E, \quad P D P A / M W C N T-\beta-$ CD/GCE OPDPA (oxidized at $1.5 \mathrm{~V}$ )/MWCNTs- $\beta-\mathrm{CD} / \mathrm{GCE}$ and OPDPA (oxidized at $0.9 \mathrm{~V}) / \mathrm{MWCNTs}-\beta-\mathrm{CD} / \mathrm{GCE}$ in $5 \mathrm{mM} \mathrm{Fe}(\mathrm{CN})_{6}{ }^{3-} / \mathrm{Fe}(\mathrm{CN}){ }_{6}{ }^{4-}$ and $0.1 \mathrm{M} \mathrm{KCl}$.

Fig. 4 shows cyclic voltammograms of the modified electrode in a $\left[\mathrm{Fe}(\mathrm{CN})_{6}\right]^{3-}$ $/\left[\mathrm{Fe}(\mathrm{CN})_{6}\right]^{4-}$ solution, before and after the polymer film oxidation. The modified electrode with PDPA/MWCNTs- $\beta$-CD shows higher currents relative to MWCNTs- $\beta-C D$. Although the current increases with the polymer oxidation (OPDPA/MWCNTs- $\beta$-CD) at $0.9 \mathrm{~V}$, and $\triangle \mathrm{Ep}$ decreases, oxidation at $1.5 \mathrm{~V}$ considerably decreases the current, due to higher resistance caused by oxidation at higher potentials.

However, it seems that the accessible surface area also increased with the polymer film oxidation at $0.9 \mathrm{~V}$. As FESEM images of the polymer film coated on MWCNTs- $\beta$-CD/GCE show, before and after oxidation (Fig. 5), a higher 
MWCNT content appears after oxidation and, due to the existence of a polymer film around it, it seems to be a specific surface area. Therefore, it is concluded that the sensitivity increases after oxidation.

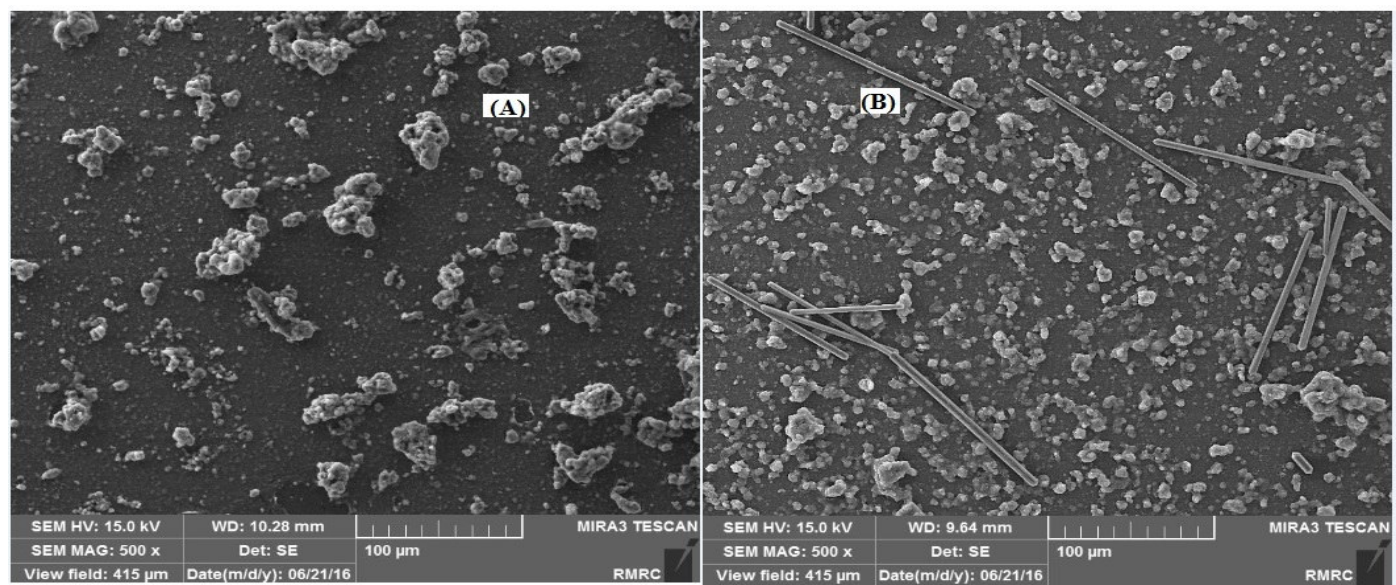

Figure 5. SEM images of (a) PDPA/MWCNT- $\beta-C D / G C E$, and (b) OPDPA/MWCNTs$\beta-\mathrm{CD} / \mathrm{GCE}$.

\section{Electrochemical behavior of ceftazidime at various electrodes}

The electrochemical oxidation behavior of ceftazidime was investigated in 0.15 $\mathrm{M} \mathrm{HClO}_{4}$ at bare GCE, PDPA/GCE, MWCNT/GCE, PDPA/MWCNTs/GCE, PDPA/MWCNT- $\beta$-CD/GCE and OPDPA/MWCNTs- $\beta$-CD/GCE, by differential pulse voltammetry, and the results are shown in Fig. 6 . At the bare GCE, nearly nothing is seen in the voltammogram, but a very small oxidation peak was observed at $0.52 \mathrm{~V}$ for ceftazidime oxidation at GCE modified with PDPA. The current increased at MWCNT/GCE and MWCNT- $\beta-C D / G C E$. However, further increase in PDPA/MWCNT- $\beta$-CD/GCE was seen, due to the synergistic effects of MWCNT and PDPA; additionally, the peak potential shifted to a more negative potential $(0.51 \mathrm{~V})$, but the higher current was seen at OPDPA/MWCNTs- $\beta-C D / G C E$. These changes showed that OPDPA/MWCNTs$\beta-\mathrm{CD} / \mathrm{GCE}$ not only merges the high conductivity and electrocatalytic effect of MWNTs, and also of PDPA, with the susceptibility of $\beta$-CD to create inclusion complexes with ceftazidime, but also the capability of the oxidized polymer for increasing the current. This behavior also diminished the background current in the oxidized polymer to the best analytical features, and the low detection limit for this sensor.

\section{pH effect}

Phosphate buffers in the $\mathrm{pH}$ range from 2 to 7 were utilized to examine the $\mathrm{pH}$ effect on ceftazidime oxidation at the modified electrode surface (Fig. 7). The response currents diminished with higher $\mathrm{pH}$ values, so, acidic media such as $\mathrm{H}_{2} \mathrm{SO}_{4}, \mathrm{HClO}_{4}, \mathrm{HNO}_{3}, \mathrm{HCl}, \mathrm{H}_{3} \mathrm{PO}_{4}$ and $\mathrm{CH}_{3} \mathrm{COOH}$ were analyzed. The best response was achieved in $0.15 \mathrm{M} \mathrm{HClO}_{4}$. Therefore, ceftazidime determination was administrated in $0.15 \mathrm{M} \mathrm{HClO}_{4}$, using OPDPA/MWCNT- $\beta-\mathrm{CD} / \mathrm{GCE}$. 


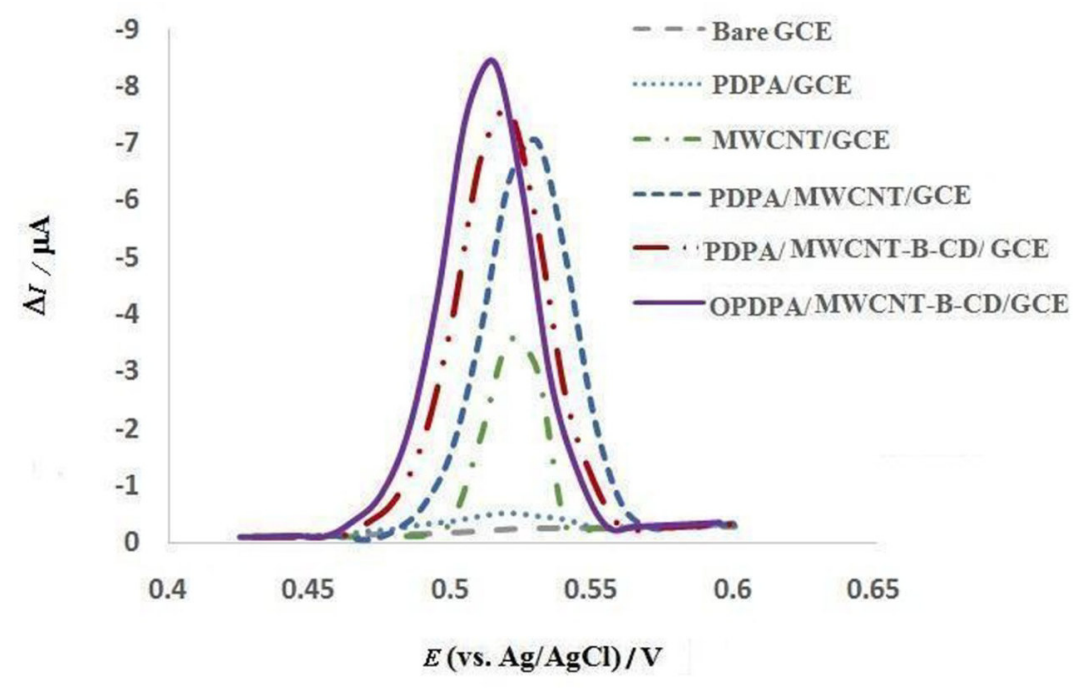

Figure 6. Differential pulse voltammograms of bare GCE, PDPA/GCE, MWCNTs/GCE, PDPA/MWCNT/GCE, PDPA/MWCNT- $\beta$-CD/GCE and OPDPA/MWCNT- $\beta$-CD/GCE in $0.15 \mathrm{M} \mathrm{HClO}_{4}$ and $5.0 \mu \mathrm{M}$ of ceftazidime (blank subtracted).

\section{Time and potentials accumulation effect}

The potentials accumulation effect was examined in the limit of -0.6 to $+0.2 \mathrm{~V}$, and also in open circuit position. The greatest response current was achieved with open circuit option. Influence of time accumulation on ceftazidime oxidation peak current was also studied by DPV. An increase in the adsorption time to 200 s conducted to higher currents; after that, the current stayed constant. Therefore, $240 \mathrm{~s}$ was selected as adsorption time. This verifies the existence of ceftazidime adsorption onto the modified electrode surface.

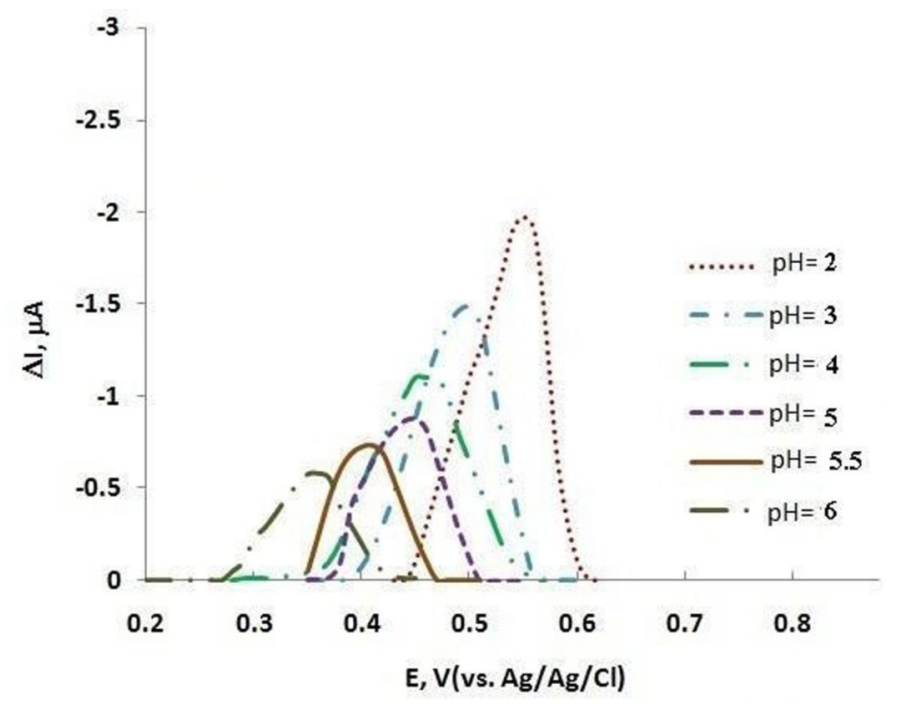

Figure 7. Differential pulse voltammograms of OPDPA/MWCNT- $\beta-\mathrm{CD} / \mathrm{GCE}$, at different $\mathrm{pH}$ values. 

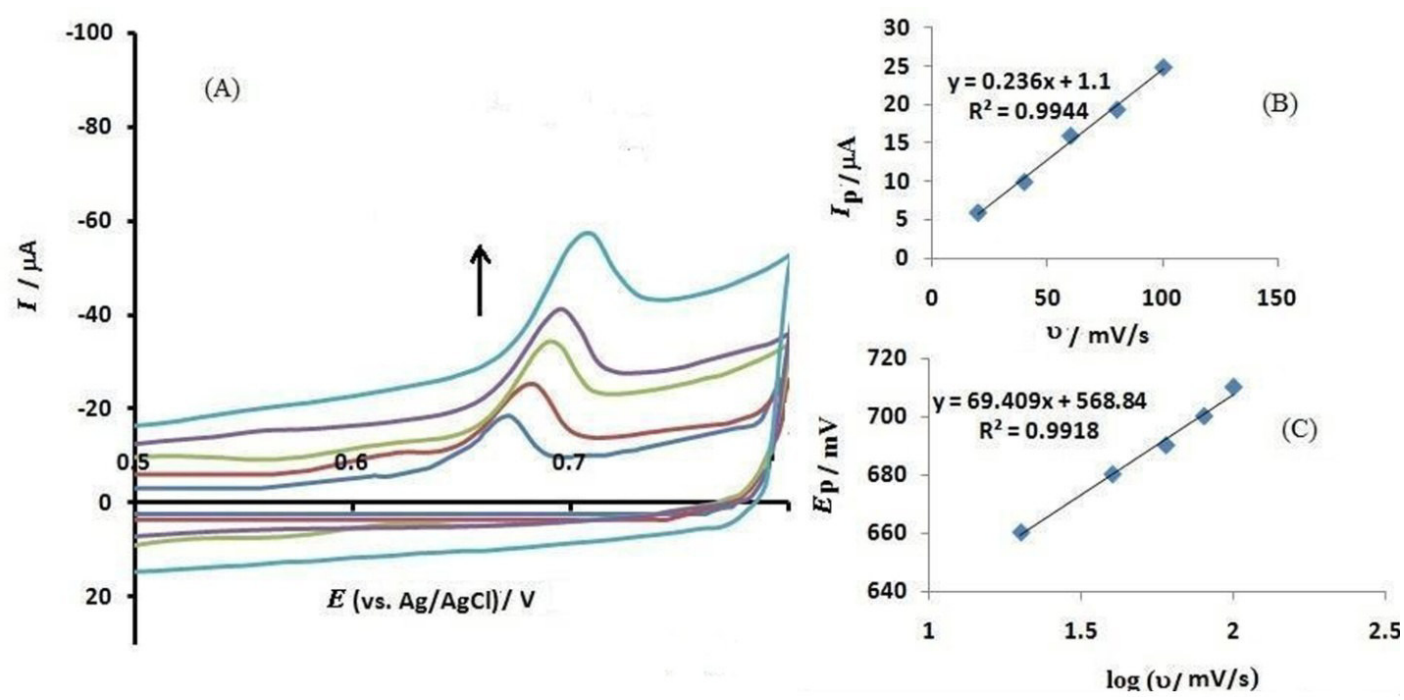

Figure 8. (a) Cyclic voltammograms of OPDPA/MWCNT- $\beta-C D / G C E$ at different scan rates; inner to outer is 20 to $100 \mathrm{mVs}^{-1}$, (b) linear dependence of the anodic peak current (Ipa) on scan rates from 20 to $100 \mathrm{mVs}^{-1}$, and (c) $\mathrm{E}_{\mathrm{p}}$ plot versus $\log$ (scan rate).

\section{Effect of scan rate}

The scan rate effects were studied on both the peak current and the peak potential. Fig. 8 shows cyclic voltammograms of ceftazidime oxidation at different scan rates. It is seen that there is a good linear relationship between the peak current and the scan rate, with a regression equation of $\mathrm{I}_{\mathrm{pa}}(\mu \mathrm{A})=0.236$ $v(\mathrm{mV} / \mathrm{s})+1.1\left(\mathrm{R}^{2}=0.9944\right)$. Again, the adsorption property of ceftazidime on the modified electrode is shown via the mentioned relationship.
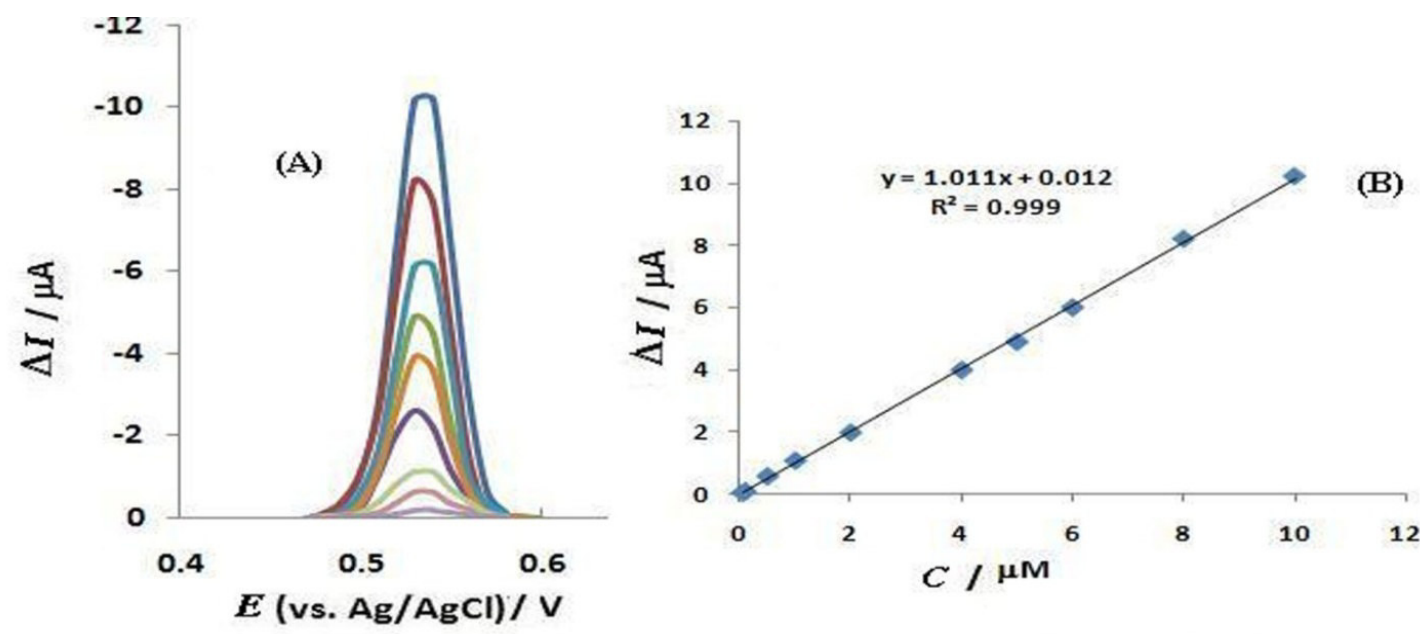

Figure 9. (A) Differential pulse voltammograms of ceftazidime at OPDPA/MWCNT- $\beta$ $\mathrm{CD} / \mathrm{GCE}$, inner to outer: $0.05,0.1,0.5,1.0,2.0,5.0,6.0,8.0$, and $10.0 \mu \mathrm{M}$, and (B) calibration curve for ceftazidime in $0.15 \mathrm{M} \mathrm{HClO}_{4}$, scan rate of $33.3 \mathrm{mV} / \mathrm{s}$, and accumulation time of $240 \mathrm{~s}$, at open circuit situation.

The peak potential also varied with the scan rate, as $\mathrm{E}_{\mathrm{p}}$ slope vs. the scan rate logarithm was equal to 69.409, considering Laviron equation (32): 


$$
E p=E^{0}+\left(\frac{2.303 R T}{\alpha n F}\right) \log \frac{\alpha n F}{R T k_{S}}+\left(\frac{2.303 \mathrm{RT}}{\alpha \mathrm{nF}}\right) \log (v)
$$

During ceftazidime oxidation, the amino group at aminothiazole substituent was oxidized to the imino radical and, during this process, it lost one electron and one proton. Then, two radicals were coupled, and a dimer was produced (10).

The electron transfer coefficient $(\alpha)$, with the assumption of $n=1$, due to the above mentioned mechanism, was 0.85 .

\section{Calibration curve, detection limit, reproducibility, stability and selectivity}

The OPDPA/MWCNT- $\beta$-CD/GCE constructed electrode was applied for ceftazidime determination, using AdDPV, under optimized experimental conditions. The peak currents increased with the rise in ceftazidime concentration from 0.05 to $10.0 \mu \mathrm{M}$, as the linear regression equation of $\mathrm{I}_{\mathrm{p}}(\mathrm{nA})=1.011 \mathrm{C}(\mu \mathrm{M})$ $+0.012\left(\mathrm{R}^{2}=0.9994\right)$ shows. The results are shown in Fig. 9. The detection limit can be calculated from the $3 \mathrm{~S}_{\mathrm{b}} / \mathrm{m}$ equation, where $\mathrm{S}_{\mathrm{b}}$ is the standard deviation of 10 replicate of the blank solution, and $\mathrm{m}$ is the slope of the regression equation. This obtained value was $1.0 \times 10^{-9} \mathrm{M}$. As the results of Table 1 demonstrate, the analytical efficiency of this electrode is comparable to the previously reported works for ceftazidime determination.

Table 1. Detection limits of various electrochemical methods for ceftazidime determination.

\begin{tabular}{lccc}
\hline \multicolumn{1}{c}{ Electrode materials } & $\begin{array}{c}\text { Linear range } \\
(\mathbf{M})\end{array}$ & $\begin{array}{c}\text { Detection limit } \\
(\mathbf{M})\end{array}$ & References \\
\hline $\begin{array}{l}\text { Pd-Au nanoparticle decorated carbon } \\
\text { nanotube/GCE }\end{array}$ & $5.0 \times 10^{-8}-5.0 \times 10^{-5}$ & $1.0 \times 10^{-9}$ & {$[8]$} \\
GCE (DPV) & $4.0 \times 10^{-6}-8.0 \times 10^{-5}$ & $6.0 \times 10^{-7}$ & {$[9]$} \\
Square wave voltammetry & $4.0 \times 10^{-6}-2.0 \times 10^{-4}$ & $1.0 \times 10^{-6}$ & {$[9]$} \\
$\begin{array}{l}\text { Molecular imprinting } \\
\text { recognition sites on multiwall carbon }\end{array}$ & $2.0 \times 10^{-9}-5.0 \times 10^{-7}$ & $5.5 \times 10^{-10}$ & {$[10]$} \\
nanotube & $5.0 \times 10^{-7}-7.0 \times 10^{-6}$ & & {$[10]$} \\
$\begin{array}{l}\text { Poly-L-lysine modified hanging } \\
\text { mercury drop electrode }\end{array}$ & $7.0 \times 10^{-10}-5.1 \times 10^{-9}$ & $1.0 \times 10^{-10}$ & {$[11]$} \\
$\begin{array}{l}\text { Hanging mercury drop electrode } \\
\text { OPDPA/MWCNT- } \beta-C D\end{array}$ & $1.0 \times 10^{-8}-1.5 \times 10^{-7}$ & $5.0 \times 10^{-9}$ & {$[12]$} \\
\hline
\end{tabular}

The sensor reproducibility was studied by ceftazidime determination of 0.5 and $5.0 \mu \mathrm{M}$, for five replica determinations, and the relative standard deviation of the peak currents was obtained as $1.5 \%$ and $1.7 \%$, respectively.

The sensor stability was investigated with its response determination for ceftazidime, every two days. The response was decreased to $90 \%$, which was its higher result, after 5 days, and to $75 \%$, after 10 days.

The effect of some other substances, among mineral and drugs, which probably can interfere on ceftazidime determination, was determined using ceftazidime oxidation peak of $5.0 \mu \mathrm{M}$. The tolerance limit defined as the external ion concentration led to an error smaller than $3.0 \%$ for ceftazidime determination. 
The results are shown in Table 2. As it can be seen, most of the species have no interference on the determination by the constructed sensor.

\section{Determination of ceftazidime in biological and pharmaceutical samples}

To estimate its applicability, the constructed electrode was used to determine ceftazidime spiked in blood serum and intramuscular injection samples. The results are shown in Table 3. The statistical t-test was used to evaluate the existence of systematic errors in the data. The results showed that there are no systematic errors in ceftazidime determination. The recoveries of this method were reported in the range from $95 \%$ to $104 \%$.

Table 2. Tolerable concentration of the various substances in ceftazidime determination, using OPDPA/MWCNT- $\beta-\mathrm{CD} / \mathrm{GCE}$.

\begin{tabular}{cc}
\hline Species & $\begin{array}{c}\text { Concentration } \\
\left(\mathbf{m g ~ L} \mathbf{~ L}^{-1}\right)\end{array}$ \\
\hline \begin{tabular}{c}
$\mathrm{Ca}^{2+}, \mathrm{Cu}^{2+}, \mathrm{Mn}^{2+}, \mathrm{Ba}^{2+}, \mathrm{K}^{+}, \mathrm{Mg}^{2+}, \mathrm{Ni}^{2+}, \mathrm{Na}^{+}$, \\
$\mathrm{Al}^{3+}, \mathrm{Co}^{2+}, \mathrm{NO}_{3}^{-}, \mathrm{Cl}^{-}, \mathrm{F}^{-}, \mathrm{Ceftriaxone}$, \\
$\begin{array}{c}\text { Streptomycin, } \mathrm{Chloramphenicol,} \mathrm{Cefazolin,}_{\text {Theophylline, Acetaminophen }} \\
\mathrm{CO}_{3}{ }^{2-}\end{array}$ \\
\hline Cefotaxime
\end{tabular} \\
\hline
\end{tabular}

* Maximum tested concentration

Table 3. Ceftazidime determination, in blood and ampoule samples, by OPDPA/MWCNT- $\beta-C D / G C E$.

\begin{tabular}{cccc}
\hline Sample & Spiked $(\mu \mathbf{M})$ & Found $(\mu \mathbf{M})$ & Recovery (\%) \\
\hline \multirow{3}{*}{$\begin{array}{l}\text { Blood } \\
\text { serum }\end{array}$} & 0.5 & $0.48 \pm 0.07$ & 96.0 \\
\cline { 2 - 4 } & 1.0 & $1.04 \pm 0.09$ & 104.0 \\
\cline { 2 - 4 } & 4.0 & $3.8 \pm 0.1$ & 95.0 \\
\hline Ampoule & 7.0 & $7.2 \pm 0.2$ & 102.8 \\
\cline { 2 - 4 } & 0.0 & $1.04 \pm 0.06^{*}$ & 101.0 \\
& 1.0 & $2.05 \pm 0.08$ & 97.0 \\
\cline { 2 - 4 } & 3.0 & $3.95 \pm 0.15$ & \\
\hline
\end{tabular}

*The prepared solution from the ampoule sample was $1.0 \mu \mathrm{M}$.

\section{Conclusion}

In this work, PDPA film electropolymerization, onto MWCNT- $\beta$-CD modified GCE, was performed, and then the formed polymer was oxidized and applied to determine ceftazidime, with high sensitivity and selectivity. In comparison with the polymer without oxidation, the background reduced, and the signal increased. The results reported in this work show that OPDPA/MWCNT- $\beta-\mathrm{CD} / \mathrm{GCE}$ is an excellent choice for ceftazidime determination.

\section{Acknowledgments}

The authors gratefully acknowledge the Research Council of Damghan University, for the partial support of this work, and also Jaber Ebne Hayyan Pharmaceutical Company, for ceftazidime preparation. 


\section{References}

1. Farrel CD, Rowell FJ, Cumming RH. A rapid fluorescence ELISA for ceftazidime. Anal Proc. 1995;32:205-206.

2. Arun K, Saravanan C, Balachandar R, et al. UV spectrophotometric determination of ceftazidime in pure and pharmaceutical formulation. $\mathrm{J}$ Chem Pharm Res. 2010;2:424-431.

3. Hiremath B, Mruthyunjayaswamy BH. Development and validation of spectrophotometric methods for determination of ceftazidime in pharmaceutical dosage forms. Acta Pharm. 2008;58:275-285.

4. Mahramyari S, Pourbasheer E, Banaei A, et al. Simultaneous spectrophotometric determination of ceftazidime and sulbactam using multivariate calibration methods. RSC Adv. 2014;4:41039-41044.

5. Fabre H, Blanchin MD, Kok WT. Liquid chromatography with amperometric detection for the determination of cephalosporins in biological fluids. Analyst. 1988;113:651-655.

6. Tyczkowska KL, Seay SS, Stoskopt MK, et al. Determination of ceftazidime in dolphin serum by liquid chromatography with ultraviolet-visible detection and confirmation by thermospray liquid chromatography-mass spectrometry. J Chromatogr B. 1992;576:305-313.

7. Wang R, Chen LR, Jia ZP, et al. Simultaneous enantiomeric separation of ceftazidime and cefriaxone sodium by capillary electrophoresis. Chin J Anal Chem. 2002;30:1070-1073.

8. Shahrokhian S, Salimian R, Rastgar S. Pd-Au nanoparticle decorated carbon nanotube as a sensing layer on the surface of glassy carbon electrode for electrochemical determination of ceftazidime. Mater Sci Eng C. 2014;34:318-325.

9. Tarinc D, Dogan-Topal B, Golcu A, et al. Electrochemical investigation and determination of ceftazidime in pharmaceutical dosage forms and human urine. J Anal Chem. 2014;69:899-908.

10. Torkashvand M, Gholivand MB. Construction of a new electrochemical sensor based on molecular imprinting recognition sites on multiwall carbon nanotube surface for analysis of ceftazidime in real samples. Sens Actuat BChem. 2016;231:759-767.

11. Ferreira VS, Zanoni MVB, Fogg AG. Cathodic stripping voltammetric determination of ceftazidime with reactive accumulation at a poly-L-lysine modified hanging mercury drop electrode. Anal Chim Acta. 1999;384:159166.

12. Ferreira VS, Zanoni MVB, Fogg AG. Cathodic stripping voltammetric determination of ceftazidime in urine at a hanging mercury drop electrode. Microchem J. 1997;7:115-122.

13. Rahman M, Kumar P, Park D-S, et al. Electrochemical sensors based on organic conjugated polymers. Sensors. 2008;8:118-41.

14. Yin T, Wei W, Zeng J. Selective detection of dopamine in the presence of ascorbic acid by use of glassy-carbon electrodes modified with both 
polyaniline film and multi-walled carbon nanotubes with incorporated $\beta$ cyclodextrin. Anal Bioanal Chem. 2006;386:2087-2094.

15. Zarei K, Teymori E, Kor K. Very sensitive differential pulse adsorptive stripping voltammetric determination of 4-nitrophenol at poly (diphenylamine)/multi-walled carbon nanotube- $\beta$-cyclodextrin-modified glassy carbon electrode. Int J Environ Anal Chem. 2014;94:1407-1421.

16. Yang C-Y, Chen S-M, Tsai T-H, et al. Poly(Diphenylamine) with multiwalled carbon nanotube composite film modified electrode for the determination of phenol. Int J Electrochem Sci. 2012;7:12796-12807.

17. Santhosh P, Manesh KM, Gopalan A, et al. Novel amperometric carbon monoxide sensor based on multi-wall carbon nanotubes grafted with polydiphenylamine-Fabrication and performance. Sens Actuat B-Chem. 2007;125:92-99.

18. Unnikrishnan B, Ru P-L, Chen S-M, et al. Nitrite determination at electrochemically synthesized polydiphenylamine-Pt composite modified glassy carbon electrode. Sens Actuat B-Chem. 2013;177:887-892.

19. Ragupathy D, Gopalan A, Lee K-P. Layer-by-layer electrochemical assembly of poly(diphenylamine)/phosphotungstic acid as ascorbic acid sensor. Microchim Acta. 2009;166:303-310.

20. Zhuang Z, Li J, Xu R, et al. Electrochemical detection of dopamine in the presence of ascorbic acid using overoxidized polypyrrole/graphene modified electrodes. Int J Electrochem Sci. 2011;6:2149-2161.

21. Qi H, Zhang C. Simultaneous determination of hydroquinone and catechol at a glassy carbon electrode modified with multiwall carbon nanotubes. Electroanalysis. 2005; 17:832-838.

22. Umasankar Y, Periasamy AP, Chen S-M. Electrocatalysis and simultaneous determination of catechol and quinol by poly(malachite green) coated multiwalled carbon nanotube film. Anal Biochem. 2011;411:71-79.

23. Wang SF, Xu Q. Square wave voltammetry determination of brucine at multiwall carbon nanotube-modified glassy carbon electrodes. Anal Lett. 2005;38:657-671.

24. Wang Z, Li S, Lv Q. Simultaneous determination of dihydroxybenzene isomers at single-wall carbon nanotube electrode. Sensors Actuators B: Chemical. 2007; 127:420-425.

25. Lu Z, Lu C, Meng Q. An inclusion complex of $\beta$-cyclodextrin with mnt anion $(\mathrm{mnt}=$ maleonitriledithiolate) studied by induced circular dichroism. $\mathbf{J}$ Incl Phenom Macrocycl Chem. 2008;61:101-106.

26. Alarcon-Angeles G, Guix M, Silva WC, et al. Enzyme entrapment by betacyclodextrin electropolymerization onto a carbon nanotubes-modified screen-printed electrode. Biosens Bioelectron. 2010;26:1768-1773.

27. Shen $Q$, Wang $X$. Simultaneous determination of adenine, guanine and thymine based on $\beta$-cyclodextrin/MWNTs modified electrode. J Electroanal Chem. 2009;632:149-153.

28. Jia D, Dai J, Yuan H, et al. Selective detection of dopamine in the presence of uric acid using a gold nanoparticles-poly(luminol) hybrid film and multi- 
walled carbon nanotubes with incorporated $\beta$-cyclodextrin modified glassy carbon electrode. Talanta. 2011;85:2344-2351.

29. Kor K, Zarei K. Electrochemical determination of chloramphenicol on glassy carbon electrode modified with multi-walled carbon nanotubecetyltrimethylammonium bromide-poly(diphenylamine). J Electroanal Chem. 2014;733:39-46.

30. Jia D, Dai J, Yuan H, et al. Selective detection of dopamine in the presence of uric acid using a gold nanoparticles-poly (luminol) hybrid film and multiwalled carbon nanotubes with incorporated $\beta$-cyclodextrin modified glassy carbon electrode. Talanta. 2011;85:2344-2351.

31. Ofer D, Crooks RM, Wrighton MS. Potential Dependence of the conductivity of highly oxidized polythiophenes, polypyrroles, and polyaniline: Finite windows of high conductivity. J Am Chem Soc. 1990;112:7869-7879.

32. Laviron E. General expression of the linear potential sweep voltammogram in the case of diffusionless electrochemical systems. J Electroanal Chem. 1979;101:19-28. 